\title{
Chapter 2 \\ Active Citizenship Programmes for Unemployed Young Adults with Low Skills in Southern Europe: Participation, Outreach, and Barriers
}

\author{
George K. Zarifis
}

\section{Introduction}

Europe is, and further will be, facing new challenges related to the consequences of demographic change. Among other socio-demographic transformations, population ageing is inevitable in most European states due to long-term demographic trends. Therefore, social policies are focusing more and more on the circumstances and effects of active social lives, essentially encouraging longer working lifetimes (European Commission 2012). Nevertheless, what about those adults who are exposed to socio-economic disadvantages? Moreover, has the vulnerability of certain social groups like the long-term unemployed changed due to the socio-economic transformations of the last decades in Europe? How have policy changes that were introduced as a response to new social and economic structures affected the social vulnerability of those groups, and in particular low-skilled or low-qualified young adults who remain out of work (and education) for too long?

Lifelong Learning (LLL) and active citizenship have recently been a major preoccupation of those considering policy options in the European Union. In European policy documents (European Commission 1998, 2011), active citizenship has been interpreted as specific skills, attitudes and knowledge that have to be acquired through education. The political aim is to create feelings of belonging, participation and democracy through social activities and learning. Even if the European education system appears to have been successful in enhancing active citizenship in terms of participation in educational initiatives and educational attainment, some particularly vulnerable areas remain. The pledges and aims of 'Europe2020'include two priorities. The first is to decrease the rate of early leavers from education and training, and the second is to reduce the proportion

\footnotetext{
G. K. Zarifis $(\bowtie)$

Department of Education, School of Philosophy and Education, Faculty of Philosophy, Aristotle University of Thessaloniki, Thessaloniki, Greece

e-mail: gzarifis@edlit.auth.gr
} 
of people at risk of poverty. According to the European Commission (2012) high quality adult education and highly trained adult educators in particular, can enhance the chances of early leavers from initial education and training to enter labour market through upgrading their skills and qualifications. The potential to stable income will reduce the quantity of population at-risk-of-poverty or exclusion.

The development of relevant policies and targeted initiatives for young unemployed adults with low skills have not passed unnoticed in southern Europe for the last decade. However, and despite the existing policies and strategies, most countries in the region do not place active citizenship programmes for low-skilled adults as a priority. The latest PIAAC results, the high influx of migrant and refugee populations in the area, the rising unemployment, poverty, and most of all the low participation rates in adult education, particularly among vulnerable social groups, has placed the issue back on the policy agenda (Zarifis 2019).

Based on an ad-hoc analysis of the accessibility of adult education as part of the research report on adult education in the EU for the Horizon 2020 EduMAP project, ${ }^{1}$ this chapter provides an in-depth look on the socio-economic reasons behind the low participation rates of young adults (aged 18-30) in active citizenship programmes in southern Europe, with some country examples. The departure point for this chapter is the broad research on adult education in the EU (EDUMAP Deliverable 2.1 2017). The specific focus of the research is on vulnerable young people, and in particular the report aims to highlight the extent to which AE and LLL initiatives have been effective for engaging and re-engaging vulnerable (disadvantaged young) people, and facilitating their social inclusion across EU28 countries. The concept of active citizenship (AC) is employed to provide a better understanding of social inclusion and participation of vulnerable young people, where $\mathrm{AC}$ is seen as related to the following dimensions: social, political or economic dimensions of participation and engagement.

In the chapter I argue that despite the unfavourable socio-economic conditions and the lack of state support, many countries in the region are showing signs of resurgence particularly through the development of initiatives at local and regional levels, as well as the challenges and the complications that many of these initiatives have to face due to low participation, lack of effective outreach policies, and existing barriers to access. Ad-hoc analysis in this respect proves useful because it allows to make a query at any time, select the data sources, and determine how data will be presented. What is presented in this chapter is a totally customized form of analysis with data that is extracted from national agencies (ministries of education, ministries of employment, and other relevant national authorities), national, regional and local AE providers as well as EUROSTAT. Ad-hoc analysis allows for a deeper dive to find the answer to a specific query. In this case it explains some of the variables involved in low participation of young low-qualified adults in active citizenship

\footnotetext{
${ }^{1}$ More details on EduMAP are available at https://projects.tuni.fi/edumap//. EduMAP (No 693388) was funded under the European Union's Horizon 2020 Research and Innovation Programme. The opinions of the author of this chapter do not represent those of the European Commission or the EduMAP Consortium.
} 
programmes. Along the same line, ad-hoc reporting provides a quick answer in its own report, without waiting for regular, standard analysis. But the two work together. They each have their own purpose, with ad-hoc reporting providing a different level of insight to support decision making.

\section{The Impact of Socio-Political State of Affairs in the Region}

It took 10 years with a series of terrorist attacks in major European cities, a lasting economic crisis with severe social repercussions, the influx of a large number of war refugees and economic migrants and the opportunistic rise of the far right, for the policy rhetoric to shift towards the need for an education that encourages empowerment and emancipation. This rhetoric was encompassed in the term "active citizenship". The term was endorsed in the European Council and European Commission's joint report about the "New priorities for European cooperation in education and training" (Official Journal of the European Union 2015), but also in the Paris Declaration on "Promoting citizenship and the common values of freedom, tolerance and non-discrimination through education" (EU Ministries of Education 2015). In European policy documents, however, active citizenship is interpreted as specific skills, attitudes and knowledge (i.e. measured learning outcomes) that can be acquired through education. The EU'spolitical aim is to create feelings of belonging, participation and democracy through social activities and learning. Growing ethnic and religious diversity in Europe, however, poses both opportunities and challenges to European policy-makers and societies. It is expected that this diversity will continue to increase. At the same time, recent studies (Van Driel et al. 2016) show that intolerance and social exclusion are increasing, with some migrant groups feeling alienated. This is leading to incidences of social unrest. So how can adult education prepare societies for dealing with these phenomena?

Southern European member states have an expressed interest in developing or expanding relevant policies and practices. However, the general economic and sociopolitical outlook in the majority of the European south, has a persisting -if not intensified- effect on adult participation in education in general. This tendency is more evident among young adults with low skills, hence those with ISCED level 0-2.The Greek adult education and VET sector for example has been strongly affected by very low and decreasing public spending, due to strict fiscal consolidation. Adult participation in lifelong learning in Greece remains very low and has tended to stagnate over time. It stood at $3.0 \%$ in 2014, compared to an EU average of $10.7 \%$. Some groups of people, such as the lower skilled young adults (ISCED level 0-2) - with a participation rate of barely $0.4 \%$ in 2014, compared to an EU average of $4.4 \%$ - or older people and those living in isolated, remote and sparsely populated areas have less access to training (OECD 2016a). Recent legislation in the adult education sector in Greece indicates the intention to revert to the educational policy from the pre-2010 period. There is still considerable room to increase efficiency and effectiveness at virtually all levels of adult education (basic, initial and continuing VET). 
Along the same line the fragile recovery of the Portuguese economy, the rates of unemployment, adult participation in learning, and educational attainment are still low, particularly those young adults who are low qualified. In spite of (adult) education policies in the last decade, results achieved seem to be insufficient to reduce the distance between Portugal and other European Union countries (OECD 2016b). The stress upon economic development, even if including a reference to low qualified young adults, reflects the ambivalence of the role assigned to adult education. It has gone from a central pillar in some policy discourses, something that could improve economic development, to a minor position in the political, social, educational, cultural and civic agenda. Only the certification and professional qualification issues and rates have been expressively stressed in policy discourses and programmes, which is a very short concern when education is at stake (Antunes and Guimarães 2015).

For Malta it is the first time, the country's efforts in the field of adult education more generally are spearheaded by a National Lifelong Learning Strategy which was adopted in 2014. It attaches importance to the issue of up-skilling people from 20-64 and beyond. There has been a shift in the economy from manufacturing towards a service-oriented industry. The special emphasis is now placed on knowledge intensive work (Bacchus 2008). The National LLL Strategy document is geared to reaching targets for education set by the EU and takes into account the special conditions of a small island state. It places importance on 'employability' but it does not go beyond it to provide a more comprehensive set of guidelines for a more exclusive approach to education for active citizenship (Mayo 2012).

In Italy, the labour market is gradually emerging from the prolonged recession. However, the risk of labour market exclusion is high, particularly for the young. Although recovering, employment and unemployment are still among the worst in the OECD area. Participation of young adults in lifelong learning is very low and shows irregular progress. At the current growth rate, the ET2020 target of participation in lifelong learning (15\%) could be achieved by 2030 (ISFOL 2014). The trends towards increased participation are related largely to activities promoted by companies or, more generally, due to private (commercial or social) initiatives. Participation in lifelong learning is concentrated largely on people with highly qualified professional roles. The most significant measure is the reform of the active labour market policies. Its implementation could improve the role of employment services and prompt the unemployed to retrain (MEF 2016). However, policy interventions on these issues have often been announced, but never fully implemented.

In Cyprus adult education is a field that has gained distinct attention only within the last few years. Despite the reforms taking place, the statistics still reflect low levels of participation of young age groups. At the same time the PIAAC survey (MoEC 2016) has revealed a low level of basic skills attainment among the young adult population. Albeit the low level of basic skills of low qualified adults (ISCED 0-2), their participation is still the lowest among all other groups. The attention given to the field by the state is an indicator of the significant role adult education has to play, especially in helping overcome the current financial crisis. The National Lifelong Learning Strategy 2014-2020 is an important step toward addressing key 
challenges in the field of adult education and lifelong learning, although the implementation of planned reforms is not always on time (Papaioannou 2016).

Last but not least, in the Spanish context participation rates, educational levels, inclusion of low qualified adults in the labour market and other statistics generally point to Spain making slow progress in relation to European goals. In this sense the situation of the adult education system has declined over the last 5 years. The latest OECD report indicates that investment in education decreased from $9 \%$ to $8 \%$, well below the average of European countries (11\%) (OECD 2016c). Officials of the Ministry of Education, Culture and Sport affirm that these are figures from 2013, but the fact is that the budget has only had a small increase $-0.1 \%$ since then the educational budget has in fact decreased from EUR 53,000 million in 2009 to EUR 46,000 million in 2015 (Ministerio de Economía y Competitividad 2016). There are general statements concerning adult education and learning, but there are no initiatives to encourage people to attend adult learning.

In general the socio-political and economic outlook for most south European member states presents a paralysis in the functioning of legislative measures and the possibility of new more effective measures is yet quite far from reality. Key strengths in the policy area in this region of Europe however, include the tradition that connects adult education and learning with local communities, and the work that is been done by several NGOs particularly with young migrants and refugees as well with young ROMA population. In terms of weaknesses, it is possible to cite the lack of a culture of learning, the lack of a workforce with specific training, and in some cases the utilisation of education as a partisan issue (Zarifis 2012, 2019).

\section{Major Challenges in Programme Delivery and Relevance}

What has largely been disregarded through the years in the region, because of the intensive advocative rhetoric on skilling for the labour market that was and still is dominant, is the focus on active citizenship. The relevant rhetoric is overarched principally by those who approach adult education from the narrow perspective of the relation between vocational education and training (VET) and the needs of the labour market in skills that exclusively support human capital. Yet, the social role of adult education including that of VET has not been translated into concrete and tangible programmes and educational practices, leaving a severe, yet not unrepairable, discrepancy in programme provision. In Greece for example organising a long term lifelong learning thematic agenda for a fully pledged (as consistent, focused and structured) adult education for building social capital is essential (Zarifis 2019). Delivering a fully structured agenda for current and future skills in order to address transversal skills for personal and social development (such as citizenship, decision making, problem solving, etc.) is vital. Promoting uninterrupted forms of networking among existing lifelong learning structures and institutions (including initial and continuing VET structures and Universities, as well as schools and local communities, museums and cultural centres, libraries and sporting facilities) will 
contribute to the expansion of provision of relevant programmes. Any reform however, needs to enhance the relevance between adult educational policies with provision of active citizenship programmes, as well as the improvement of lifelong counselling and guidance for those who are socially vulnerable; hence the low skilled, migrants and long-term unemployed (Zarifis et al. 2015).

Similar evaluations in Portugal have noted that the link between adult education policy and work was the weakest dimension of provision. On the one hand, it was clear that higher educational attainment is important for economic development and the concern of increasing educational attainment rates has been stressed by a large number of international and national organisations and researchers: namely these that promote human capital theories. However, the large majority of enterprises in Portugal are micro, small or medium sized, in which employers do not value education and training and in which many workers are low educated and trained. One of the reasons pointed to explain this situation is the fact that nor employers or workers seem to consider that adult education provision improves neither productivity nor an increase in skills. Important skills are the outcome from school certification, general in character, and skills that are not specific, nor clearly linked to professional tasks or a job (Carneiro 2011). The existing Programa Qualifica launched in August 2016, only includes a short range of provisions for promoting lifelong learning policies and improving the quality of the learning processes. Therefore, this new policies directed at fostering the achievement of education and training pathways leading to qualifications (school certification and professional qualification). These pathways are based on valuing learning developed through life, through the achievement of recognition of prior learning, and the acquisition and development of competences by the attendance of education and training courses and modular training. However, this seems to be clearly insufficient when observing the cultural, economic, and civic problems that the Portuguese society is currently facing (Cavaco 2016).

In Italy the actions focused on understanding and identifying needs and motivations of learners are mainly carried out within the framework of measures providing individual training plans. Identification of current and future skills needs of employers is carried out by various bodies. Nevertheless, foresight studies are lacking for the medium and long term which would improve the development of programmes to meet the needs of the labour market. Innovation and flexibility in the delivery of learning is reflected principally in regional policies that over the past 15 years have developed regional, remote training systems and structure models of training paths (INDIRE 2013). In the territorial training projects, programmes are promoted by associations or networks of stakeholders. In the corporate projects such actions can also take very rich forms that involve the future participants in the planning process. The public policies explicitly aimed at encouraging the emergence of new demand for training -(i.e. adults at risk of social exclusion) are based primarily on measures of "compulsory training." This approach characterises all measures related to the new flexicurity policies and of "active inclusion" (poverty), as well as the policies which aim to introduce new standards of quality in productive activities, in business, in the professions (doctors, engineers, lawyers, etc.). In these cases, obtaining 
a certification and the formal fulfilment of the provisions of the law is the main motivation for participation. However, compulsory training has a cost for those who participate. It is free when it is connected to flexicurity policies and active inclusion (SPRAR 2016).

In Malta while drafting the National Youth Policy for 2015-2020, three separate but interlocking pillars were identified and provided the background and context for the development of this policy (MEDE 2014). The first of these pillars is the reality of the lives of young people in Malta today and how coherent policies, effectively implemented and actively supported, can help young people in meeting their needs and aspirations. The second pillar is the development of youth policy over the past 20 years at both national and European level. The evolution and implementation of youth policy has provided us with not only the aims and objectives towards which such policy should be directed, but also the underlying principles, methodologies, tools and administrative and financial supports. The third pillar is the Government's policy for greater democratic participation, equitable economic and social progress for all, and inclusive change. In most conventional accounts of youth transition, the route from full-time education to the labour market is often perceived as the most critical. A successful economic transition, it is argued, forms the basis for the ultimate attainment of domestic independence, household and/or family formation. In senior policy circles, therefore, it is understandable that a crucial aim of the education system should be vocational preparation. Education, however, embraces a broader mission than merely aligning the education system with the needs of the economy. In fact such an alignment is no simple task, because healthy economies are dynamic and in a state of constant flux and change (NFCHE 2013). Young people, therefore, need to be equipped with something rather more than sets of occupationally-defined competences. They need the skills, competences and attitudes required to adapt to rapidly changing economic and social conditions. The acquisition of such navigation skills should now be regarded as an essential element of a good education. As far as participation in education is concerned, attention has been drawn to the problem of illiteracy and dropout rates (Mayo 2007).

A challenge for adult education in Cyprus is the need to bridge the world of education and training with the real world of work. The National Lifelong Learning Strategy for 2014-2020 is focused on the promotion of vocational education and training especially targeted at young adults. The implemented and planned developments and reforms are a serious step towards combating skills mismatch and youth unemployment. The Cypriot Human Resource Development Agency (HRDA) is promoting research activities (skills forecasting) for understanding and harmonising the supply of skills to the needs of the economy, with no reference to social and civic skills (Cyprus Government 2015). Along this line, there is not much activity targeted at the identification and understanding of learners' needs. Most of the programmes offered in formal adult education, especially those offering second-chance education to low educated young adults (i.e., Evening Gymnasiums-Lyceums, Evening Technical Schools), do not use tools for assessing the learners' needs and adjusting to them. In contrast, their curricula and their operational framework are 
directly imposed by the Ministry of Education and Culture, leaving little space for adjustments (World Bank 2014).

Early school leaving remains a challenge in Spain. In 2014, about 39\% of men and $28 \%$ of women among the 25-34 year-olds did not have an upper-secondary qualification 4 , which is twice the OECD average. Nevertheless, the past 4 years have seen a substantial shrink in early school leaving, as a consequence of increased enrolment in vocational education and training. A significant proportion of youth in Spain have poor literacy skills (18\%) and poor numeracy skills (23\%) (OECD 2016c). Even if Spanish youth perform better than the group aged 30-54 years which represents an improvement with respect to the previous generation, they still score poorly compared to other OECD countries. Young people who are neither employed nor in education or training (NEETs) risk being left permanently behind in the labour market. This risk is especially high for the relatively large share of low-skilled NEETs (i.e. those who have not finished upper secondary schooling). Many in this group live in households without any employed adults, suggesting that they are also at risk of poverty (Dolado et al. 2013). Effective policies are needed to reconnect members of this group with the labour market and improve their career prospects. While long-term unemployment among youth has risen sharply in most European countries during the crisis, higher unemployment and NEETs rates in Spain largely reflect much higher worker turnover rather than a higher prevalence of long-term unemployment. Further, the transition from education to a first stable job takes longer in Spain. The high incidence of temporary employment in Spain is found to be the main determinant of both high worker turnover and the volatility of youth employment (Scarpetta et al. 2010).

\section{Barriers to Participation and the Need for Targeted Outreach}

Most country studies in southern Europe show that the strategies implemented by most member states in the region to increase the number of young adults in education, or to reach out to disadvantaged groups of young adults, particularly those who are low skilled, concern the articulation between supply and demand of lifelong learning.

Table 2.1 below shows the varied rate of participation in adult education and lifelong learning programmes in the selected six southern European member states among young adults. The table shows that the majority of the countries on which this chapter focuses score the lowest levels of adult participation in any type of formal education between 2010 and 2015. Although any statistical analysis cannot make direct reference to how formal, non-formal or informal education is approached by the respondents in order to identify themselves as belonging to any of the categories for which data is collected, the numbers reveal a highly uncomfortable situation for some of these member states. 
Table 2.1 Lifelong learning participation rates of low qualified adults (ISCED 0-2) in six selected southern European countries and progress against EU2020 target and EU average

\begin{tabular}{l|l|l|l|l|l|l}
\hline & Greece & Cyprus & Italy & Spain & Portugal & Malta \\
\hline $\mathbf{2 0 1 5}$ & $0.4 \%$ & $1.6 \%$ & $2 \%$ & $3.6 \%$ & $4.2 \%$ & $2.4 \%$ \\
\hline $\mathbf{2 0 1 4}$ & $0.4 \%$ & $1.4 \%$ & $2.2 \%$ & $3.9 \%$ & $4.3 \%$ & $2.9 \%$ \\
\hline $\mathbf{2 0 1 3}$ & $0.4 \%$ & $1.2 \%$ & $1.5 \%$ & $4.6 \%$ & $4.6 \%$ & $2.5 \%$ \\
\hline $\mathbf{2 0 1 2}$ & $0.4 \%$ & $1.3 \%$ & $1.6 \%$ & $4.7 \%$ & $6.1 \%$ & $2.4 \%$ \\
\hline $\mathbf{2 0 1 1}$ & $0.4 \%$ & $1.3 \%$ & $1.2 \%$ & $4.7 \%$ & $7.8 \%$ & $3 \%$ \\
\hline $\mathbf{2 0 1 0}$ & $0.5 \%$ & $1.1 \%$ & $1.3 \%$ & $4.7 \%$ & $3.6 \%$ & $3.4 \%$ \\
\hline
\end{tabular}

Source: Participation rate in education and training by age, Eurostat trng_lfse_01, last updated 26 April 2016

Explanatory note: EU average participation rate for low qualified adults at the time of the EDUMAP research was $4.3 \%$. This table compares the participation rate in lifelong learning of adults aged 25-64 for those with low qualification levels (ISCED levels 0-2) between 2010 and 2015

Most south European countries, do not show any favourable conditions for increasing participation of young adults in learning (see Carneiro 2011; LucioVillegas 2012; Mayo 2012; Papaioannou 2016; Zarifis 2008). Many of them face major barriers to implementing policies to increase the number of adults participating. These barriers generally appear at all levels of adult education, but the most influential ones as Broek et al. (2010) suggest are the institutional barriers.

This is very evident in Greece where the major policy target for adult education and VET systems is to ensure the mechanisms that will endorse and improve the effectiveness of the existing national strategy for LLL, so that the ongoing as well as the planned interventions meet the local needs. This is not easy to be achieved mostly because these needs are linked to the needs of the labour market, and are not targeted to the target groups' particular needs for civic responsibility and essentially combating the risk of social vulnerability. To this end, lack of initiatives for resolving issues of access and raising adult participation rates in education appear as the main barriers. Despite the efforts and some relevant actions at policy level by the Council of Lifelong Learning, the goal to increase participation in adult education that promotes active citizenship cannot be realised without rebooting the adult education system within a strategic framework that builds a permanent link between adult education and training with the development of transversal skills. Moreover, Greece has to resolve inequalities in access to adult education which are reflected in the minimum participation of young workers, artisans and the low skilled in comparison to those with the highly skilled, the greater participation of residents of urban areas over suburban and rural areas, and in the greater involvement of young people with high level of education compared to those with lower levels of education (Zarifis 2012). In addition, the intensification of the refugee crisis in 2015 has disproportionately affected Greece as a transit country. This unanticipated increase in refugee and migration inflows, and the estimated continuation or even escalation of inflows in response to the continuing geopolitical tensions in the Middle East, undoubtedly entail an additional challenge in terms of educational opportunities for 
this particular group. PIAAC data ${ }^{2}$ also shows that a demand for raising literacy levels must be a priority. The low levels of educational attainment and qualification amongst young adults in particular reveal a deficit in building a sustainable lifelong learning approach despite the measures foreseen in the relevant laws (Zarifis 2020).

The participation barriers young low-skilled adults face in Malta is facing are also many. It has a high percentage of early school leavers (the percentage of early school leavers in Malta hovered around the 22\% mark in 2013) (MEDE 2014). In response, Malta provides an alternative learning programme at a particular centre to address students at risk of early school leaving. This centre faces the challenge of providing adult continuing education for both these students in terms of their continuing education and others not caught by this safety net. The other challenge is to bridge the digital divide and here further investment in support of adequate adult provision is necessary including support for local council initiatives in the field. Malta needs to extend and improve the quality of its multimedia library provision in different localities on the understanding that these libraries are often considered as important sources of LLL. These libraries are to serve as hives of learning activities in terms of enabling adults and youngsters to improve their digital literacy, reading and information gathering and sifting skills, important skills for both citizenship and work. It needs to invest more in the sectors of intercultural adult education given the constantly changing nature of the country's multi ethnic composition and also, as with all other countries of the world, adult education for sustainable development, the latter to be part of a holistic approach at all levels of education from cradle to grave (Mayo et al. 2008).

In Italy until recently, a policy of emergency containment prevailed concerning vulnerable groups (e.g. migrants, NEET, elderly, etc.) through specific responses and momentary interventions. Today the challenge for Italy is to define the supply of skills that the country needs to ensure participation of the country in the new industrial revolution characterised by new production models based on the embedding of intelligence in all objects of industrial production, as well as in living and working environments. Today, the creation of innovation and its use aim at human capital development, equipped with more refined qualities than those required by previous industrial eras (UE 2014). It is not just reforms are needed to face this challenge. Italy does not have a public system of adult learning and as a result adult learning does not achieve the standards of quality and extent of other countries. Public investment should respond to a support strategy of expanding the demand for training by all the population and qualification and enlargement of the offer. Some of the reforms in place (the public administration and flexicurity policies) are moving in this direction, but they are not enough. Other policies should be adopted urgently to support individual demand (from vouchers to the effective obligation of adult learning), the creation of support systems (from operator training, to research,

\footnotetext{
${ }^{2}$ Greece participated in the second round of the international survey PIAAC of OECD, for the period 2012-2016. The full results have not yet been released, however the general indicators show that adults in Greece score very low in ICT skills. The full report is available at http://www.oecd. org/publications/skills-matter-9789264258051-en.htm
} 
to the introduction of access policies to new technologies, as well as cultural infrastructures), the adoption of fiscal measures that favour social mobility (tax simplification and breaks for new businesses) and the qualification of training organisations (cutting down oligopolies, opening up to competition, encouraging their internationalisation as well as the creation of new training start-ups) (OECD 2016d). Certain barriers of accessing education and training of young low-skilled adults in Italy refer to the ability to contribute to the revival of growth and employment in a context of shrinking resources, of fiscal policy aimed at ensuring debt reduction. It is true that the policies of flexicurity and the social act have increased the potential demand for training through the concentration of public resources on vulnerable groups, but the adoption of measures supporting individual demand for training can help spread the possibility of increasing people's freedom of choice and customising routes. This could enrich the training offered and improve quality assurance. Additionally, this trend of measures to support individual demand would lead to the release of public resources and direct them to the construction of a public system of adult learning that ensures all necessary support for proper functioning of the adult education market. This includes: improved skills recognition systems, training of trainers, dissemination of information and guidance services, introduction of devices for quality control of learning and to the adoption of favourable tax policies (MLPS 2015).

In Cyprus at the moment, a major challenge for adult education that focuses on active citizenship is the planning and implementation of a special Administration of Adult Education and Lifelong Learning under the aegis of the Ministry of Education and Culture. The Administration is an opportunity for the creation of a group of adult education experts, which will lead to the promotion of reforms and developments under a unified plan. At the same time, this evolution will address the need for the creation of a database of information, data and literature on adult education on a local basis and will further promote the systematisation of the field (Papaioannou 2016). Additionally, this reform will ease the creation of a monitoring mechanism that will ensure the quality of the programmes. To address the need for the creation of a quality adult educational system, another challenge is the establishment of a legislative framework that will define and regulate adult educational staff. This reform would regulate the qualifications and the required training of the adult educational staff in a legislatively harmonised way (Zarifis 2012).

In Spain adult education has traditionally been linked to communities either in a social dimension or in relation to the local production system. While a part of this important tradition has been lost, its influence remains, as seen in the Communities of Learning operating in disadvantaged neighbourhoods such as the Polígono Sur ${ }^{3}$ (South District) in the city of Seville, and other similar initiatives spread around the country. These kinds of initiatives can be considered strengths because people find in these activities a motivation to attend learning activities (Flecha 2015). There are also some positive examples of strong collaboration between the public sector,

\footnotetext{
${ }^{3}$ See http://www.poligonosursevilla.es/opencms/opencms/
} 
workers and employers in the field of adult training that promotes civic responsibility. The Tripartite Foundation for Training in Employment in particular is a private foundation that provides training for young employed workers with low skills. The foundation is jointly governed by trade unions, employers, and the State Public Employment Service. ${ }^{4}$ There are also examples of Civil Society Organisations filling gaps in adult education and learning provision. For example, in the city of Seville important work in relation to literacy with migrant people is being taken forward by Hermandades (Fraternities) (Flecha and Puigvert 2015). A key weakness though is that there is not a strong culture of learning in the country. This can be related to relatively low levels of literacy. Based on figures from the census of 2011 it is possible to consider that $31 \%$ of the adult population in Spain is functionally illiterate. ${ }^{5}$ Other figures show that $43 \%$ of adult people have a low level of education. ${ }^{6}$ Other data on the behaviour of the population can be useful here: with figures from 2014 showing that only $33 \%$ of the population went to visit a museum, $62 \%$ read a book and 23\% attended theatre performances (Ministerio de Economía y Competitividad 2016). There is a lack of training focused on specific teaching approaches for adults. The psychology of the adult, or specific teaching methodologies used in adult learning are not seen as an important element of teacher training in the majority of Faculties of Education. There is a lack of political consensus about the fundamental building blocks of the educational system in Spain. This lack of consensus is regarded as being responsible for the relatively poor performance of the adult educational system in Spain in which early school leavers in 2015 were around 20\%. ${ }^{7}$ There also are big variations in the effectiveness of the education system across different territories in Spain ${ }^{8}$ (Lucio-Villegas 2012).

What must be stressed at this point is that given the extensive literature on barriers to learning, it is also important to relate structural factors to the perceptions of barriers perceived by individual who wish to learn. In the context of defining barriers for participation of young low-skilled adults in adult education programmes that focus on active citizenship in particular, the strategies designed to resolve the problems identified with widening participation need to aim to introduce targeted instruments that further address issues of outreach. What seems to be lacking is not the policies or the will of the governments to change existing structures, but the conditions that will eventually allow greater collaboration and commitment among various social partners and the development of a sustainable information network in southern Europe that goes beyond the issues of sources of funding and mere programme marketing (Zarifis 2008).

\footnotetext{
${ }^{4}$ See http://www.fundaciontripartita.org/Pages/default.aspx

${ }^{5}$ See http://www.ine.es/dyngs/INEbase/es/operacion.htm?c=Estadistica_C\&cid=1254736176825\& menu $=$ resultados\&idp $=1254735576508$

${ }^{6}$ See http://www.elmundo.es/espana/2015/06/12/5579fbc8268e3e26118b459d.html

${ }^{7}$ See http://ec.europa.eu/eurostat/tgm/table.do?tab=table\&init=1\&language=en $\&$ pcode=t2020_4 $0 \&$ plugin $=1$

${ }^{8}$ See http://ccaa.elpais.com/ccaa/2016/08/01/madrid/1470070603_695615.html
} 


\section{Some Recommendations}

Unemployed, low-qualified young adults in southern Europe are largely underrepresented with respect to participation in adult education programmes that focus on active citizenship. The emphasis on their vocational education hampers the awareness of the importance of their non-vocational learning. Based however on the assumption that social policy has - as a productive factor - a decisive impact on the functioning of a country's economy (OECD 2016a), it seems reasonable to involve more actors in designing social policies that address their participation in active citizenship programmes. Their participation in such programmes is very low and shows inconsistent progress. One aspect, specifically emphasised by the European Commission as an important element of a social investment strategy in this context, is "social innovation", which is defined as developing new ideas, services and models to better address social issues ${ }^{9}$. The crucial point is that this does not only refer to input from public actors, but puts a special emphasis on private actors, including civil society, to improve social services: "Greater involvement of public authorities is key to achieving sustained outcomes from social policy innovation. Promoting broader partnerships with the private sector, civil society organisations and stakeholders operating in the social economy is also essential. Social enterprises and entrepreneurship are pivotal for catalysing innovative ideas and should complement public efforts in pursuing social policy objectives" (European Commission 2015: 4). In the light of current policy initiatives in the countries presented in this chapter, raising participation of young unemployed adults with low-skills in active citizenship programmes must also consider that the way adult education for active citizenship operates must make a difference. In particular, adult education settings with strong and dynamic ties to the local community have great potential for promoting cohesion. They create a sustainable positive adult education settings atmosphere, as well as a stronger sense of belonging (Boeren et al. 2010). In addition to that relevant programmes need to create conditions for inter-ethnic cooperation and foster tolerance. Simply bringing young unemployed adults from different backgrounds together is not sufficient to reduce prejudice and develop positive intercultural relations. We need to stress that adult education needs to create the conditions for all learners and teaching staff to develop intercultural competence. Furthermore, adult teaching staff need diversity training. The intercultural competence of adult educators in Europe needs to be strengthened (Zarifis 2019). The majority of adult educators who participated in the EduMAP research suggested that they also feel weak and vulnerable when it comes to perform in learning environments with diverse audiences. The use of effective methods for creating inclusive programmes is also essential. Most south European countries still tend to use

\footnotetext{
${ }^{9}$ According to Phills et al. (2008) social innovations are new solutions (products, services, models, markets, processes etc.) that simultaneously meet a social need (more effectively than existing solutions) and lead to new or improved capabilities and relationships and better use of assets and resources.
} 
traditional teaching methods, although methods such as project-based learning, cooperative learning and peer education are becoming more common. These methods have demonstrated their value in combating intolerance. An activity that involves learners dialoguing with each other and the instructor. Beliefs, assumptions, attitudes, and perspectives are challenged and examined in the classroom where dialogue is encouraged (Zarifis 2020). Last but not least, adult education practice could benefit more from third-sector know-how. Local and international NGOs with specific expertise in the field can enhance the expertise in adult education settings, but are underutilized in both formal and non-formal adult education (Quesada et al. 2015).

\section{References}

Antunes, F., \& Guimarães, P. (2015). An inconsistent policy: Lifelong learning and adult education policy towards competitive advantage. In G. Zarifis \& M. Gravani (Eds.), Challenging the 'European area of lifelong learning'. A critical response (pp. 75-86). Dordrecht: Springer.

Bacchus, M. K. (2008). The education challenges facing small nation states in the increasingly competitive global economy of the twenty-first century. Comparative Education, 44(2), $127-145$.

Boeren, E., Nicaise, I., \& Baert, H. (2010). Theoretical models of participation in adult education: The need for an integrated model. International Journal of Lifelong Education, 29(1), 45-61.

Broek, S. D., Buiskool, B. J., \& Hake, B. (2010). Impact of ongoing reforms in education and training on the adult learning sector (2nd phase) (Final report of the study financed by the European Commission DG EAC (EAC/15/2009)). Zoetermeer: Research voor Beleid. https:// op.europa.eu/en/publication-detail/-/publication/82ebbda8-35aa-4e5a-a815-1e1e0b434e6d.

Carneiro, R. (2011). Accreditation of prior learning as a lever for lifelong learning: Lessons learnt from the new opportunities initiative, Portugal. Braga: UNESCO/MENON/CEPCEP.

Cavaco, C. (2016). Políticas públicas de educação de adultos em Portugal - a invisibilidade do analfabetismo. Laplage em Revista, 2(1), 51-62.

Cyprus Government. (2015). National reform programme 2015. http://ec.europa.eu/europe2020/ pdf/csr2015/nrp2015_cyprus_en.pdf

Dolado, J. J., Jansen, M., Felgueroso, F., Fuentes, A., \& Wölfl, A. (2013). Youth labour market performance in Spain and its determinants: A micro- level perspective (OECD Economics Department working papers, No 1039). Paris: OECD. https://doi.org/10.1787/5k487n5bfz5c-en. https:// www.oecd-ilibrary.org/economics/youth-labour-market-performance-in-spain-and-its-determi nants_5k487n5bfz5c-en.

EU (European Union)/Ministries of Education. (2015). Declaration on promoting citizenship and the common values of freedom, tolerance and non-discrimination through education. Informal meeting of European Union education ministers. https://op.europa.eu/en/publication-detail/-/ publication/ebbab0bb-ef2f-11e5-8529-01aa75ed71a1

European Commission. (1998). Education and active citizenship in the European Union. Luxembourg: Office for Official Publications of the European Communities. https://op.europa. eu/en/publication-detail/-/publication/b33ea18c-355e-4fa5-bee6-cc07194831ad.

European Commission. (2011). Action plan on adult learning: Achievements and results 2008-2010 (Commission staff working paper, SEC(2011) 271 final). Brussels: European Commission. https://ec.europa.eu/social/BlobServlet?docId=22030\&langId=en.

European Commission. (2012). EU high level group of experts on literacy (Final report). Brussels: European Commission, DG-EAC. https://op.europa.eu/en/publication-detail/-/publication/9 6d782cc-7cad-4389-869a-bbc8e15e5aeb/language-en. 
European Commission. (2015). Social policy innovation. Meeting the social needs of citizens. Luxembourg: Publications Office of the European Union. https://ec.europa.eu/social/BlobSer vlet?docId=13691\&langId=en.

Flecha, R. (2015). Comunidades de aprendizaje: sueños posibles para todas las niñas y los niños. Aula de Innovación Educativa, 241, 12-16.

Flecha, R., \& Puigvert, L. (2015). Las Comunidades de Aprendizaje: Una apuesta por la igualdad educativa. [Communities of Learning. A challenge for educational equality]. Cultura para la esperanza: instrumento de análisis de la realidad, 99, 29-35.

Horizon (2020). What is Horizon 2020? https://ec.europa.eu/programmes/horizon2020/ what-horizon-2020\#Article

INDIRE. (2013). Istruzione degli adulti. Rapporto di monitoraggio (Adult education. Monitoring report). Firenze: Indire. http://www.indire.it/lucabas/lkmw_file/Ida/Report_ Monitoraggio\%20_IDA_2011-12.pdf.

ISFOL. (2014). PIAAC-OCSE. Rapporto nazionale sulle Competenze degli Adulti PIAACOCSE. (National Report on adult skills and competencies). Roma: ISFOL. http://www.isfol.it/ piaac/Rapporto_Nazionale_Piaac_2014.pdf

Lucio-Villegas, E. (2012). What's going on? An overview of adult education policies in Spain. Journal of Adult and Continuing Education, 18(1), 77-89.

Mayo, P. (2007). Adult education in Malta. Bonn: DVV International.

Mayo, P. (2012). Adult education in Malta: Challenges and prospects. Journal of Adult Continuing Education, 18(1), 43-60.

Mayo, P., Pace, P. J., \& Zammit, E. (2008). Adult education in small states: The case of Malta. Comparative Education, 44(2), 229-246.

MEDE. (2014). Malta national lifelong learning strategy 2020. Malta: Ministry of Education and Employment.

MEF-Ministero dell'Economia e delle Finanze. (2016). Documento di Economia e Finanza 2016. Sezione III Programma Nazionale di Riforma (Economics and Finance Document 2016. Section III National Reform Programme). Roma: Ministero dell'Economia e delle Finanze. http://www.mef.gov.it/documenti-pubblicazioni/doc-finanza-pubblica/

Ministerio de Economía y Competitividad. (2016). Programa Nacional de Reformas. Reino de España 2016 [National Reform Plan. Kingdom of Spain 2016]. http://www.mineco.gob.es/ portal/site/mineco/

MLPS. (2015). XVI Rapporto sulla Formazione continua Annualità 2014-2015 (XVI Continuing vocational training survey-2014-2015). Roma: Ministero del Lavoro e delle Politiche Sociali. http://www.lavoro.gov.it/temi-e-priorita/orientamento-e-formazione/focus-on/Formazione/ Documents/XVI_Rapporto_formazione_continua_2014_2015.pdf.

MoEC. (2016). Cyprus research report on PIAAC. Nicosia: MoEC. http://www.pi.ac.cy/pi/files/ keea/pdf/Research_Report_PIAAC_FINAL_2016.pdf.

NCFHE. (2013). Implementation of quality assurance in vocational education \& training (VET) institutions. Malta: National Commission for Further and Higher Education.

OECD. (2016a). Skills matter: Further results from the survey of adult skills (OECD skills studies). Paris: OECD. http://www.oecd.org/skills/piaac/Skills-Matter-Greece.pdf.

OECD. (2016b). Society at a glance - How does Portugal compare. Paris: OECD. https://www. oecd.org/portugal/SAG2016-portugal.pdf.

OECD. (2016c). Society at a glance - How does Spain compare. Paris: OECD. https://www.oecd. org/spain/SAG2016-spain.pdf.

OECD. (2016d). Employment outlook in Italy, 2016 report. Paris: OECD. https://www.oecd.org/ italy/Employment-Outlook-Italy-EN.pdf.

OECD. (2016e). OECD economic surveys: Greece. Paris: OECD Publishing. The Executive summary of this report is available online at: www.oecd.org/eco/surveys/GRC\%202016\%20 Overview\%20EN.pdf

Official Journal of the European Union. (2015). 'Joint report of the Council and the Commission on the implementation of the strategic framework for European cooperation in education and 
training (ET 2020), new priorities for European cooperation in education and training (2015/ C417/04)', C417/25. https://eur-lex.europa.eu/legal-content/EN/TXT/?uri=CELEX:5201 5XG1215(02)

Papaioannou, E. (2016). Empowerment of adults through second chance education: A case study. (Unpublished doctoral thesis). Nicosia: Open University of Cyprus.

Phills, J. A., Jr., Deiglmeier, K., \& Miller, D. T. (2008). Rediscovering social innovation. Stanford Social Innovation Review, Fall 2008, 33-43.

Quesada, C., Círasso, A., Pineda, P., \& Janer, A. (2015). Training for innovation in Spain. Analysis of its effectiveness from the perspective of transfer of training. In S. Bohlinger, U. Haake, C. H. Jørgensen, H. Toiviainen, \& A. Wallo (Eds.), Working and learning in times of uncertainty. Challenges to adult, professional and vocational education (pp. 183-195). Rotterdam: Sense Publishers.

Scarpetta, S., Sonnet, A., \& Manfredi, T. (2010). Rising youth unemployment during the crisis: How to prevent negative long-term consequences on a generation? (OECD social, employment and migration working papers no. 106). Paris: OECD. https://doi.org/10.1787/5kmh79zb2mmven. https://www.oecd-ilibrary.org/social-issues-migration-health/rising-youth-unemploymentduring-the-crisis_5kmh79zb2mmv-en.

SPRAR. (2016). Rapporto annuale. Sistema di protezione per richiedenti asilo e rifugiati (Annual report. Protection system for refugees and asylum seekers). Roma: Ministerodegli Interni. http://www.sprar.it

UE. (2014). Programma Operativo Nazionale. Per la Scuola - competenze e ambienti per l'apprendimento (National Operational Programme on education. Competences and environments for learning), C(2014)9952 - 17/12/2014 http://www.istruzione.it/allegati/2014/ PON_14-20.pdf

Van Driel, B., Darmody, M., \& Kerzil, J. (2016). Education policies and practices to foster tolerance, respect for diversity and civic responsibility in children and young people in the EU (NESET II report). Luxembourg: Publications Office of the European Union. https://op.europa. eu/en/publication-detail/-/publication/abe4b8dc-ffa8-11e5-b713-01aa75ed71a1/language-en.

World Bank. (2014). Analysis of the function and structure of the ministry of education and culture of the Republic of Cyprus. http://enimerosi.moec.gov.cy/archeia/1/ypp156

Zarifis, G. K. (2008). Bringing learning closer to home: The value and impact of the Lisbon strategy for strengthening the role of local learning centres and partnerships in southeastern Europe. International Journal of Lifelong Education, 27(6), 641-657. https://doi. org/10.1080/02601370802408308.

Zarifis, G. K. (2012). Adult participation in education in South-Eastern Europe: An elaboration on the study report for the assessment of the impact of ongoing reforms in education and training on the adult learning sector. Journal of Adult and Continuing Education, 18(1), 27-42. https:// doi.org/10.7227/JACE.18.1.4.

Zarifis, G. K. (2019). Rethinking adult education for active participatory citizenshipandresistance in Europe. In L. Tett \& M. Hamilton (Eds.), Resisting neoliberalism in education-local, national and transnational perspectives (pp. 225-238). Bristol: Policy Press/Bristol University Press.

Zarifis, G. K. (2020). Participation in literacy programs for adults with low skills in Southeastern Europe. In D. Perin (Ed.), The Wiley handbook of adult literacy (pp. 361-380). New York: Wiley.

Zarifis, G. K., Fotopoulos, N., \& Zanola, L. (2015). Study on the quality and effectiveness of the social dialogue in the area of VET in Greece. Athens: IME-GSEVEE. Available in Greek. https://imegsevee.gr/wp-content/uploads/2018/04/KOINONIKOS-DIALOGOS-Final.pdf. 
Open Access This chapter is licensed under the terms of the Creative Commons Attribution 4.0 International License (http://creativecommons.org/licenses/by/4.0/), which permits use, sharing, adaptation, distribution and reproduction in any medium or format, as long as you give appropriate credit to the original author(s) and the source, provide a link to the Creative Commons licence and indicate if changes were made.

The images or other third party material in this chapter are included in the chapter's Creative Commons licence, unless indicated otherwise in a credit line to the material. If material is not included in the chapter's Creative Commons licence and your intended use is not permitted by statutory regulation or exceeds the permitted use, you will need to obtain permission directly from the copyright holder. 